\title{
Culture, gender, and the first memories of black and white American students
}

\author{
JOSEPH M. FitzGERALD \\ Wayne State University, Detroit, Michigan
}

\begin{abstract}
A pattern of delayed offset of childhood amnesia in Asian cultures has been attributed to the influence of the collectivist orientation of these cultures. To explore the generality of this finding, black and white American students were compared in two studies. A culture $\times$ gender interaction was observed in both studies; black women were approximately 11-16 months older at the time of their first memory than were black men, white women, and white men. In the second study, analyses of memory content indicated that black women were least likely to report personal experiences and most likely to report experiences from family or wider social contexts. Overall, black participants rated their memories as more vivid, but there were culture $\times$ gender interactions for ratings of emotional intensity and coherence. We consider multiple influences on age at first memory, including distal influences, gender themes in self-construal, and proximal influences on search criteria.
\end{abstract}

Euro-American adolescents tend to report that they were younger at the time of their first memories than do Asian adolescents. This result has been attributed to a delayed offset of childhood amnesia in collectivist Asian cultures such as China and Korea. The generality of this finding is limited, however, because Asian cultures are the only collectivist cultures studied. African and Middle Eastern cultures are examples of collectivist cultures that have not been studied. Because contemporary AfricanAmerican culture is believed to have maintained at least some aspects of collectivism, the comparison of AfricanAmerican and Euro-American cultures may be useful for understanding cultural influences. This article reports two studies providing the first systematic effort to study childhood amnesia in black and white college students. Although the pattern of cultural differences in age at first memory is more complex than originally anticipated, the results of the two studies replicate each other and provide an important complement to earlier studies. In this introduction, we review the status of cross-cultural work in the area of childhood amnesia to provide the groundwork for the comparison of black and white Americans.

The basic phenomenon of childhood amnesia is a welldocumented lack of memories from the earliest childhood years (Henri \& Henri, 1898), even though children possess basic memory skills at birth (Bauer, 2007). The core issue in childhood amnesia research has become why memories from early childhood are retained at a far lower rate than one would expect on the basis of traditional memory models and retention data (Rubin \& Wenzel, 1996). Once children reach the age of 6 years, the average age for reported first memories is 3.5 years. The proportion of memories recalled that occur between 3.5 and 7 or 8 years of age is also lower than expected (Bauer, Burch, Scholin, \& Guler, 2007; Bruce, Dolan, \& Phillips-Grant, 2000; Fitzgerald, 1991; Kihlstrom \& Harackiewicz, 1982; C. Peterson, Grant, \& Boland, 2005).

Our concern is with the development of autobiographical memory in cultural contexts. In this vein, Nelson and her colleagues (Nelson, 1986; Nelson \& Fivush, 2000, 2004) developed a sociocultural perspective on memory development termed memory socialization. The socialization of memory (Nelson \& Fivush, 2000) occurs in the home, the preschool, and the playground. Such diverse origins produce diverse outcomes in autobiographical memory and concepts of the self. Studies of cultural variability suggest that not all cultures work with the same script or goals for memory socialization. Furthermore, not everyone in a given culture has the same scripts or memory goals (Wang, 2006).

The dialogues between parents and children have long been of interest to developmental psychologists (Miller, Potts, Fung, Hoogstra, \& Liang, 1990; Nelson, 1986). Within the context of middle-class America, Fivush and her colleagues conducted research on memory development and mother-child dialogues about past events. They identified patterns, referred to as reminiscence styles, that varied from high to low elaboration (Fivush, Haden, \& Reese, 1996, 2006; Reese \& Fivush, 1993). High elaboration is typically contrasted with high levels of repetition and directing. They found reliable differences within the several samples of middle-class Western parents. They interpreted their data in the sociocultural framework of Vygotsky (1978), in which the movement in development is from the external to the internal. In this case, motherchild dialogues provide the means by which children de- 
velop the capacity to independently form coherent narratives about the personal past. High levels of maternal elaboration in those dialogues are associated with the early emergence of autobiographical competence (Fivush et al., 2006; Jack, MacDonald, Reese, \& Hayne, 2009).

A series of studies have provided comparisons of the age and content of earliest memories of Caucasian individuals in Western societies and the memories of Asian individuals living in either Asian or Western societies. Mullen (1994) first reported that Asian college students are an average of 6-16 months older than Euro-Americans at the time of their first memories. These results have often been replicated in studies comparing Euro-Americans/New Zealanders with Asian individuals either born in China, Korea, Japan, and India or of Asian descent but born in America/New Zealand (see Bauer, 2007, and Wang, 2003, for recent reviews).

Cultural variation in several psychological processes has been studied in the context of Eastern and Western societies. These data have been interpreted in models variously referred to as collectivism-individualism (Hofstede, 1991), interdependent-independent (Markus \& Kitayama, 1991), or allocentric-idiosyncratic (Triandis, 1995). According to these models, Western cultures are individualistic; the focus is on the rights, responsibilities, and values of individuals. In such cultures, social relations operate at the periphery, and individual behavior and development are highly decontextualized. Late 20th century American culture is often offered as the prototypical individualistic culture. In contrast, Asian cultures are characterized as collectivist and are portrayed as more communal, with a strong focus on group identity, from which individuals derive meaning. Cultures vary, however, in the particular in-groups that provide the context for individual behavior (Triandis, 1989). In some collectivist cultures, the focus may be the mother-child relationship; in others, it may be the extended family or clans.

Subsequent research on collectivism-individualism has altered some features of the original conceptualization. Rather than representing opposing poles of a single dimension, collectivism and individualism are seen as distinct uncorrelated/orthogonal dimensions. Additional dimensions have been hypothesized that provide useful characterizations of cultures. These include relationism, familialism, spirituality, and harmony control. These dimensions are hypothesized to contribute to cultural differences in the products, values, goals, and self-construals of cultures. Thus, observed cultural differences may reflect both individualism and collectivism or different factors altogether. Furthermore, the relationship between Asian cultures and other collectivist cultures, such as African, Middle Eastern, or Hispanic cultures, is largely unexplored.

How are the broad differences between cultures reflected in differences in the offset of childhood amnesia? One view is that memory differences between independent and interdependent cultures reflect differences in maternal elaboration about past events in mother-infant dialogues. The finding of lower levels of maternal elabo- ration in Asian samples has been reported in several cultures, including China, India, and Korea (see Fivush \& Haden, 2003, for a review). Wang (2006) proposed that the emphasis on collectivism in interdependent cultures leads to a diminished emphasis on the role of the self during early socialization, thus delaying the development of autobiographical memory. Western mothers take the role of supporting, commenting upon, and elaborating the narrative efforts of preschool children. They ask their children to tell more stories and encourage and support efforts to elaborate those stories. In contrast to Western mothers, Chinese, Indian, and Korean mothers are more directing, controlling, and repetitive and are less elaborative. They ask their children to recall fewer stories and steer narratives in the direction of normative content and rule-oriented behavior (Wang, 2006).

There are also differences in early experience within Eastern cultures. In a study of the impact of China's policy of limiting parents to a single child, Wang, Leichtman, and White (1998) examined the impact of increased self-focus on the emergent sense of the self, as well as the content of and age at first memories. They compared Chinese young adults who (1) were either only children or children with a sibling, (2) were raised in rural or urban settings, (3) were male or female, and (4) either attended preschool or did not. The results are fairly summarized as demonstrating that within the Chinese context, only children were younger at the time of first memories and that those memories were more specific and self-focused. Age at first memory was predicted by gender, cohort, preschool attendance, and urban/rural family. The mean age at first memory for the only children and those with a sibling were 39 and 47.7 months, respectively. This difference is equivalent to the differences between Asian and Western cultures.

The comparative study of African-American and EuroAmerican cultures provides an avenue for clarifying the impact of culture on the development of autobiographical memory. African cultures are collectively oriented, and there is considerable evidence to support the view that individuals in the majority of African nations scored lower on individualist self-construal and higher on collectivism than did Americans (Oyserman, Coon, \& Kemmelmeier, 2002). The comparison of black and white Americans, however, has proven to be less clear-cut. In their metaanalysis of self-construal studies, Oyserman et al. found no differences in individualism/independence between blacks and whites. In fact, blacks generally rated themselves higher on individualism. It should be noted that the number of participants in these studies has often been small, so that even in a meta-analysis, the conclusions are tentative. The results for collectivism in the meta-analysis were even more ambiguous. On composite measures, blacks are not significantly more collectivist, but when the analyses are restricted to the core aspects of collectivism, black samples score in the direction of higher collectivism. Other researchers have found stronger evidence for the importance of collectivism in African-American culture (Coon \& Kemmelmeier, 2001). Because many of the studies employed African-American college students, 
Table 1

Sample Sizes and Average Ages of Participants

\begin{tabular}{|c|c|c|c|c|c|c|c|c|c|}
\hline \multirow[b]{3}{*}{ Group } & \multicolumn{3}{|c|}{ Total Participants } & \multicolumn{3}{|c|}{ Study 1 Sample } & \multicolumn{3}{|c|}{ Study 2 Sample } \\
\hline & \multirow[b]{2}{*}{$N$} & \multicolumn{2}{|c|}{ Age } & \multirow[b]{2}{*}{$N$} & \multicolumn{2}{|c|}{ Age } & \multirow[b]{2}{*}{$N$} & \multicolumn{2}{|c|}{ Age } \\
\hline & & $M$ & $S D$ & & $M$ & $S D$ & & $M$ & $S D$ \\
\hline Blacks & 393 & & & 175 & & & 45 & & \\
\hline Men & 87 & 22.9 & 7.53 & 75 & 20.4 & 2.74 & 19 & 19.47 & 2.19 \\
\hline Women & 306 & 22.1 & 6.21 & 98 & 20.4 & 2.38 & 26 & 19.69 & 1.83 \\
\hline Whites & 746 & & & 200 & & & 52 & & \\
\hline Men & 276 & 20.7 & 4.57 & 100 & 19.8 & 2.37 & 22 & 20.05 & 2.27 \\
\hline Women & 470 & 19.6 & 3.41 & 99 & 19.2 & 1.91 & 30 & 19.00 & 0.83 \\
\hline
\end{tabular}

some samples may be biased to endorse individualism more than would the general population.

The issue of gender differences is also important in the study of earliest memories. In reviewing the available studies in Western cultures, Bauer (2007) noted that although gender differences were not evaluated statistically in all cases, women almost always report earlier first memories. Fivush and Buckner (2003) attributed this to gender differences in reminiscing style; mothers are more elaborative with girls than with boys. Rubin (2000) gathered data from a dozen studies to evaluate the distribution of over 11,000 early (not earliest) memories at ages of 10 years and younger. In contrast to studies of earliest memories, he found no gender difference in the distribution of early memories.

In her cross-cultural work, Mullen (1994) reported that men were older at the time of their first memories independently of ethnicity, although the difference was not always statistically significant. MacDonald, Uesiliana, and Hayne (2000), however, reported an interaction of culture and gender, with a strong effect of gender within a sample of Chinese immigrants to New Zealand, but not for whites or native Maoris; in that study, Chinese women, but not men, reported older first memories. The mean for the Chinese women in that study was 73.3 months, as compared with 42.4 months for Chinese men, 42.9 months for white women, and 32.6 months for Maoris. This appears to be the only report of a significant culture $\times$ gender interaction in which women reported being older at the time of their first memory.

\section{STUDY 1}

Our concern is with the impact of cultural variation on memory development. The ultimate goal is to understand the role of culture in autobiographical memory development. Age at first memory is a marker of that development. How general is the impact of collectivism and interdependence reported in studies of Asian cultures? As was noted above, African-American culture provides a unique opportunity to study the independent-interdependent framework. Across the available studies, African-American cultures rate higher on indices of collectivism. This result is hypothesized to reflect the heritage of West African cultures preserved through the slavery experience and 20thcentury dispersal. African-Americans, however, do not differ from Euro-Americans on independence (Oyserman et al., 2002) or individualism (Gaines et al., 1997). By comparing African-American and European-American cultures in the present studies, we sought to explore the impact of these two themes on the age at first memory (Studies 1 and 2), as well as the content of the memories that they report (Study 2).

\section{Method}

Participants. A total of 1,635 students at a large Midwestern university with a racially, ethnically, and economically diverse student population participated. In keeping with practice in the field, we use the term culture and refer to our participants as black and white, consistent with a socially constructed system of divisions within the American population (Twenge \& Crocker, 2002). The data were collected during an optional screening/testing session at the beginning of the semester over five consecutive terms. The sample included 1,139 black and white students. Table 1 provides basic demographic information. The sample sizes for culture/gender subgroups in the total sample vary because fewer black men were enrolled. Data collection continued in order to increase the number of black men in the sample. Although the population estimates were all stable, the validity of inferential statistics with such different sample sizes is problematic. To create four groups with more homogeneous sample sizes and average ages, data from individuals age 30 or over were discarded, along with randomly selected data from the three categories with large sample sizes. ${ }^{1}$

Procedure. Students received notices concerning the availability of an online prescreening/mass-testing option to earn $1 \mathrm{~h}$ of credit toward a course requirement. During the session, the participants logged onto a secure Web site and provided demographic information including family income, age, ethnicity, religious affiliation, number of siblings, birth order, head of household, the earliest memory question, and a series of survey items unrelated to the present research.

Items and Scoring. The analyses focus on the following item.

We would like you to take a moment to think of your earliest childhood memory. Close your eyes and think of your earliest memory, and then as close as you can approximate please give your best estimate of your age at the time of the event in years and months. For example, if you were 30 months old at the time of the event that would be written here as 2 years 6 months.

Some participants only provided a year, with no reference to months. As in prior studies (Mullen, 1994), we scored these events as occurring at the midpoint of the year. If a participant recorded 3 in the year's column and left months blank, this was scored as 42 months.

\section{Results and Discussion}

As is illustrated in Figure 1, on average, black women were older at the time of their first memories. Table 2 presents the results of the moderated multiple regression 


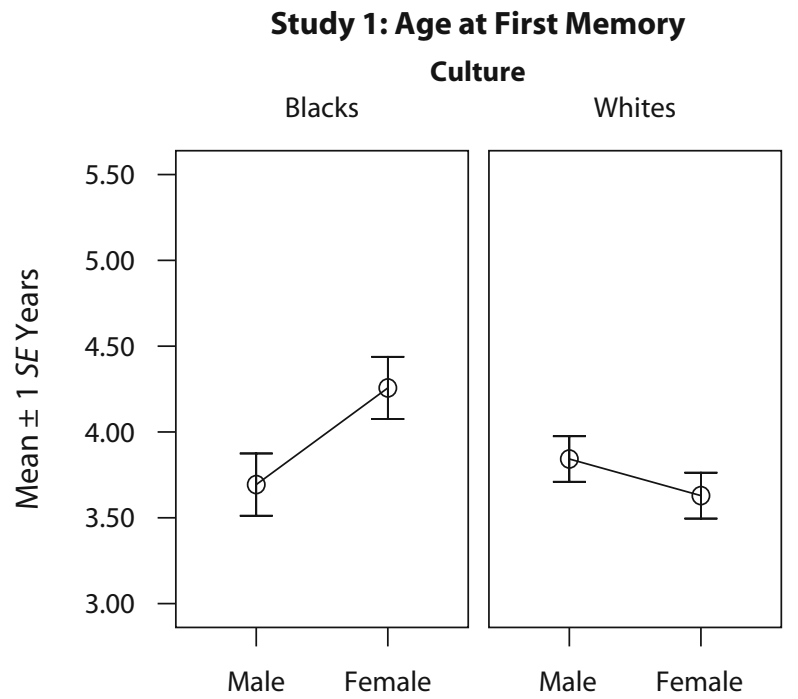

Gender

Study 2: Age at First Memory

Culture

Blacks
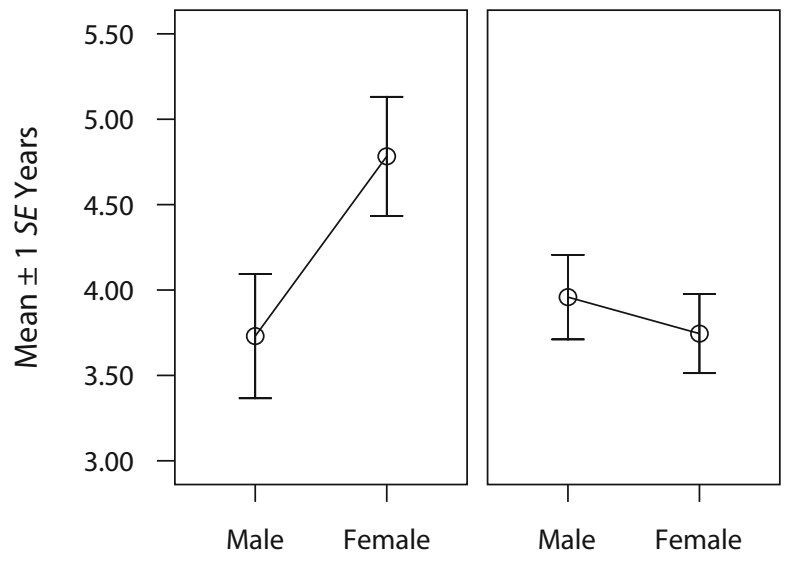

Gender

Figure 1. The culture $\times$ gender interaction for Studies 1 and 2 . The dependent variable is the individual's reported age at the time of his or her first memory.

in the first column. Moderated regression is designed to test the impact of a variable on the relationship between two other variables. There were no significant main effects of culture or gender. The culture $\times$ gender interaction, however, was significant. The interaction was decomposed using post hoc $t$ tests; means are presented in terms of years. Black women reported that they were significantly older at the time of their first memory $\left(M_{\text {Years }}=4.40, S E=0.20\right)$ than did black men $\left(M_{\text {Years }}=\right.$ $3.61, S E=0.13)[t(185)=2.94, p<.001, d=0.33]$; the mean for black women was also higher than that for white women $\left(M_{\text {Years }}=3.64, S E=0.13\right)[t(198)=2.94, p<$ $.01, d=0.43]$. Neither the comparison of white men with white women $[t(198)=-1.13, p=.500, d=-0.10]$ nor that of white men with black men $[t(173)=-0.68, p=$ $.50, d=-0.10]$ reached significance. Interactions are frequently interpreted in terms of the concept of moderation. Change in the $d$ statistic is an index of moderation. Although it appears that gender is moderating the effect of culture on age at first memory $(\Delta d=0.53)$, culture appears to moderate the effect of gender on age at first memory $(\Delta d=0.43)$.

Demographic variables such as culture or gender sometimes serve as surrogates either for another demographic variable or for some physical or psychological variable. The issue can be thought of in terms of mediation analysis (Baron \& Kenny, 1986; Kenny, 2009): Is there any variable that would substitute for the coded interaction? Several variables were evaluated as potential mediators or covariates, including maternal and paternal education, number of siblings, head of household, family income, and parents' work status. If the hypothesized mediator was categorical, logistic regression was employed. The interaction predicted three demographic variables - family income, father's highest grade level, and head of household - but none of these demographic variables predicted age at first memory. Thus, a meditational model was not supported for any of the variables. As is indicated in Table 2, none of these variables functioned as effective covariates, either alone or in combination.

The distribution of head of household in the present sample is noteworthy in terms of the comparison of the present sample with Caucasian and African-American populations in the United States. Participants were asked which of the following described their household during their childhood: mother and father both present, mother only, father only, someone other than mother or father. Consistent with U.S. census data, participants reported few households headed by either fathers or others, so these few cases were eliminated from this analysis. In our sample, $25 \%$ of the white participants and $36 \%$ of the black participants reported living in mother-only households. In 1985, the closest available point to the average birth date of our participants, the U.S. census reported that $10 \%$ of white Americans and $55 \%$ of black Americans lived in mother-only households. Thus, the black and white samples in this study were more similar than the national norms.

The results are consistent with a sociocultural view of earliest childhood memory in that age at first memory is influenced by both culture and gender. They are most similar to the data reported by MacDonald et al. (2000), who also reported an interaction between culture and gender for age at first memory. Such data challenge the specific hypothesis that cultural background influences the development of memory in childhood in a consistent fashion for all members of a particular culture or gender group. In a similar vein, Wang et al. (1998) reported that age at first memory varied due to preschool attendance and urban versus rural environment, as well as status as an only child. More specifically, Wang (2001a) reported finding a gender $\times$ culture interaction in a study of Chinese and American college students. She found effects of gender for several autobiographical memory and self-concept 
Table 2

Outcome of Age at First Memory Regression Analyses:

Unstandardized Regression Coefficients and Proportion of Variance of Interaction

\begin{tabular}{lccccc}
\hline \multicolumn{1}{c}{ Measure } & $\begin{array}{c}\text { No } \\
\text { Control } \\
(n=373)\end{array}$ & $\begin{array}{c}\text { Education } \\
\text { Controls } \\
(n=336)\end{array}$ & $\begin{array}{c}\text { Income } \\
\text { Control } \\
(n=373)\end{array}$ & $\begin{array}{c}\text { Family } \\
\text { Controls } \\
(n=336)\end{array}$ & $\begin{array}{c}\text { Combined } \\
\text { Controls } \\
(n=321)\end{array}$ \\
\hline $\begin{array}{l}\text { Father's highest grade } \\
\text { Mother highest grade }\end{array}$ & & .094 & & & .098 \\
Family income & & & & & -.083 \\
Number of siblings & & & -.008 & & .041 \\
Both parents present & & & & .000 & .044 \\
Culture & .147 & .145 & .025 & .001 & .000 \\
Gender & .576 & .526 & .301 & .174 & .011 \\
Culture $\times$ gender & $-.757^{*}$ & $-.841^{*}$ & $-.656^{*}$ & $-.770^{*}$ & $-.779^{*}$ \\
$\Delta r^{2}$ interaction & $.014^{* *}$ & $.016^{* *}$ & $.011^{* *}$ & $.015^{* *}$ & $.013^{* *}$ \\
$R^{2}$ model & $.023^{* * *}$ & $.029^{* * *}$ & $.026^{* * *}$ & $.025^{* * *}$ & $.034^{* * *}$ \\
\hline${ }^{*} p<.019 . \quad{ }^{* *} p<.05$. & ${ }^{* * *} p=.038$. & & & &
\end{tabular}

variables for Chinese students, but not for Americans. All these findings provide clear evidence of diversity in memory development among subgroups within a population. Before entertaining hypotheses to explain the particular pattern observed here, we turn to the second study.

\section{STUDY 2}

In Study 2, we extended the study of the culture $\times$ gender interaction by examining the nature of reported memory content and participant ratings of their memory experiences, referred to here collectively as metamemory. In addition, we replicated Study 1 in a different setting for data collection, face to face in the laboratory, rather than the anonymity of the Internet. The first aim was to replicate the culture $\times$ gender interaction for age at first memory. The second aim was to identify variables that might be driving the interaction.

The availability of content analysis and metamemory data was an important addition to the research. By analyzing these data, we hoped to gain insight into the type of criterion that individuals from different cultures employ in the retrieval process. Autobiographical retrieval processes must have a criterion for either satisfaction or termination (Conway \& Pleydell-Pearce, 2000), and individuals or groups have differing criteria for a successful or unsuccessful search. Identification of such differences may provide for advances in understanding observed differences in age at first memory and the role of context in the development of autobiographical memory.

Several methods have been developed to study the content of autobiographical memories and the subjective experience of autobiographical recall that we refer to here as metamemory. In Study 2, participants provided relatively limited protocols that ranged from very scant (6 words) to informative (133 words); the mean was $27.4(S E=1.7)$. The methods employed by Wang et al. (1998) and Wang (2001a) incorporated the conceptual approach used by Waldfogel (1948). In the Waldfogel system, coders assign each memory report into one of five categories: personal experiences/feelings, family experiences, neighborhood experiences, school experiences, and sociocultural events. The coder evaluates the focus of the storyteller. For ex- ample, two individuals might both report the birth of a sibling. One individual might focus on the arrival of a new family member and interactions among family members, whereas another might tell the story as a personal experience about feeling ignored because they had to stay with a relative. We also employed more quantitative elements found in Mullen (1994) and Pennebaker, Francis, and Booth (2007). In addition, participants rated their memory experiences using a series of scales that are referred to as the Autobiographical Memory Questionnaire (AMQ). The scales are described in more detail below.

\section{Method}

Participants. The sample consisted of college students recruited from the same university as in Study 1 . Table 1 provides the sample size and demographic information. Two participants did not provide accounts of the event but did provide age and AMQ data.

Procedure. Students participated in a comparative study of their personal memories. Participants provided their earliest childhood memory, everyday memories, and flashbulb memories. Earliest memories were always requested first. After providing each memory, the participants completed a series of memory-rating scales. Comparative data are reported elsewhere.

Measures. The participants read and signed an informed consent form that outlined the tasks they would be asked to perform, including the nature of the memories they would be asked to report. The instructions for reporting first memory were the same as those employed in Study 1, with the addition of a request to describe the event. A form provided a space with five lines drawn across the page. Most students confined themselves to that space, but some provided longer descriptions.

Autobiographical Memory Questionnaire. The participants completed the AMQ rating scales immediately after writing their description of the event. These scales are part of a collection of items termed the AMQ (Rubin, 2005). As can be seen in Table 6, the items included here referenced emotional, visual and auditory imagery, coherence of the memory recalled, belief in the accuracy of the memory, and a sense of reliving the event. These variables were included here to assess their value for understanding the retrieval history and the subjective nature of first memory experiences in different groups. The items were presented in the form of Likert scales ranging from 1 to 7 .

Rating scales. In addition to the data provided by the participants, naive observers rated the memory descriptions on a series of scales designed to capture as much of the content as possible. Raters worked with typed versions of the memory descriptions. Three different sets of coders provided ratings. Some additional ratings are not reported here, because they were largely redundant with 
Table 3

Summary Table of Differences

\begin{tabular}{|c|c|c|c|c|}
\hline Variable & Gender Effect & Culture Effect & $\begin{array}{l}\text { Black Male vs. } \\
\text { Black Female }\end{array}$ & $\begin{array}{c}\text { Black Female vs. } \\
\text { White Female }\end{array}$ \\
\hline Age at first memory & & & black females (+) & black females $(+)$ \\
\hline Personal experience & & & black males $(+)$ & white females $(+)$ \\
\hline Wider context & & & black females $(+)$ & black females $(+)$ \\
\hline Word count & & blacks $(+)$ & & \\
\hline Self-references & & blacks $(+)$ & & \\
\hline Other references & females $(+)$ & & & \\
\hline Other/self ratio & females $(+)$ & & & \\
\hline Negative affect (Mullen, 1994) & & black males $(+)$ & & \\
\hline No affect (Mullen, 1994) & & white males $(+)$ & & \\
\hline Specificity (Mullen, 1994) & & & & black females $(+)$ \\
\hline Coherent (AMQ) & & & black males $(+)$ & \\
\hline Intensity (AMQ) & & & & black females $(+)$ \\
\hline
\end{tabular}

Note-AMQ, Autobiographical Memory Questionnaire.

those that are reported or did not add to our understanding of the outcome.

One set of raters categorized the memories into one of the five categories employed by Waldfogel (1948), Wang et al. (1998), and Wang (2001a). The categories were personal experience, family experience, school experience, neighborhood experience, and sociocultural events. The raters were blind to both the demographics of the participant and the age at their first memory and had not rated the memories on any other scales. They were trained using a set of memories not included in the present analysis until they reached agreement with the author $90 \%$ of the time. They agreed with each other $85 \%$ of the time, and disputes were resolved through discussion. The majority of memories fell into the personal and family experience categories. In part, because of the small number of memories in the other categories, and consistent with Wang et al., we report the following contrasts: personal/nonpersonal, family/nonfamily, and wider context/not wider context.

Microsoft Word was used to count the total number of words, the number of references to the self, and the number of references to others. We included possessive adjectives (my, mine, their) in the appropriate self and other references, along with names, reference by role (mother), and pronouns.

A third set of raters performed content ratings (Mullen, 1994). Each memory was categorized as (1) a specific memory (the time my dad caught a shark), (2) a recurring or generic event (fishing with my dad), or (3) a sensory impression (the smell of fish). The content was also rated for the mention of trauma, the presence of positive or negative affect in the protocol, and the location and individuals included. Two raters scored $30 \%$ of the protocols. The kappa values all exceeded 84 .

\section{Results and Discussion}

The results presented here are somewhat complex Table 3 provides a summary of the results, which the reader may find to be a useful roadmap in following the focal results.

Age at first memory. The findings for age at first memory replicated those in Study 1. In a moderated hierarchical multiple regression, no main effects of gender or culture were found. There was clear evidence of moderation when the culture $\times$ gender interaction was entered $\left(r^{2}=.05, B=1.34 ; t=2.18, p=.03\right)$. Once again, there was a gender effect within the black sample for age at first memory $[t(46)=-2.21, p=.03, d=0.72]$; the black women were older at the time of the recalled event $\left(M_{\text {Years }}=4.86, S E=0.35\right)$ than were the men $\left(M_{\text {Years }}=\right.$ $3.74, S E=0.36)$. The gender effect in the white sample was not significant $(d=-0.13)$. A culture effect was observed within the female sample $[t(55)=2.65, p=.014$, $d=0.71]$; the black women were older at the time of their memories than were the white women $\left(M_{\text {Years }}=3.75\right.$, $S E=0.35)$. The effect for culture with the male sample was not significant $(d=-0.14)$.

Memory volume and self/other references. The black participants wrote longer $\left(M_{\text {Words }}=31.78\right)$ than did the white participants $\left(M_{\text {Words }}=24.35\right)$; culture was the only significant factor in the multiple regression for volume $\left(r^{2}=.04, B=9.34 ; t=2.13, p=.04\right)$. We noted several differences related to self and other references. Blacks made more self-references $\left(M_{\text {Self }}=4.57\right)$ than did the white participants $\left(M_{\text {Self }}=3.28\right)$, and females made more references to others $\left(M_{\text {Other }}=2.43\right)$ than did males $\left(M_{\text {Other }}=1.48\right)$, but these differences were not significant when controlling for the total number of words. For the other/self ratio, we found a higher ratio for females $\left(M_{\text {Ratio }}=.70\right)$ than for males $\left(M_{\text {Ratio }}=.42\right)$; this difference was significant when controlling for the total number of words $\left[F(1,94)=6.80, M S_{\mathrm{e}}=.27, p=\right.$ $.01]$.

Content analysis. The content analysis using the scales and items employed by Mullen (1994) revealed few main effects or interactions of culture and gender (see Table 4). First, the black participants were more likely to indicate that the story involved a first experience $\left[\chi^{2}(1, N=96)=\right.$ $6.18, p=.01]$. Second, white females were more likely to make reference to their fathers than were black females $\left[\chi^{2}(1, N=96)=3.96, p=.05\right]$. We observed fewer traumas than did Mullen; the only clear difference between studies was that Mullen recruited from ethnic groups not included here. The most common event category was play, a category that Mullen did not report. We replicated her finding that, contrary to Freud's (1901/1953) predictions, participants are more likely to refer to negative affect than to positive affect. Men were more likely than women to mention negative affect, but there was an interaction with culture. Black men were more likely to mention negative affect $(26 \%)$ than were white men $(0.0 \%)\left[\chi^{2}(1, N=96)=\right.$ $7.18, p=.01]$. There was also an interaction for reporting no affect. White men were more likely not to mention affect $(65 \%)$ than were black men $(35 \%)\left[\chi^{2}(1, N=96)=\right.$ 
Table 4

Proportions of Participants in Content Analysis Categories

\begin{tabular}{|c|c|c|c|c|c|c|}
\hline Variable $^{\mathrm{a}}$ & Response & Blacks & Whites & Males & Females & $\begin{array}{c}\text { Mullen } \\
\text { (1994) }\end{array}$ \\
\hline \multirow[t]{2}{*}{ Focus } & Specific $^{d}$ & .98 & .87 & .93 & .93 & .85 \\
\hline & Recurring/generic & .02 & .10 & .07 & .07 & .15 \\
\hline \multirow[t]{5}{*}{ Event } & Illness ${ }^{\mathrm{b}}$ & .20 & .17 & .11 & .25 & .14 \\
\hline & Birth of sibling & .04 & .07 & .07 & .03 & .03 \\
\hline & Discipline-scolding & .07 & .02 & .04 & .05 & .02 \\
\hline & Family traditions & .07 & .02 & .07 & .02 & \\
\hline & Play & .15 & .28 & .16 & .26 & \\
\hline Trauma & Present & .15 & .06 & .13 & .10 & .23 \\
\hline \multirow[t]{6}{*}{ Location } & Home & .48 & .45 & .54 & .41 & .31 \\
\hline & Relatives home & .04 & .12 & .04 & .12 & \\
\hline & School & .15 & .09 & .07 & .14 & .11 \\
\hline & Outdoor & .18 & .28 & .23 & .25 & .31 \\
\hline & Public setting & .13 & .15 & .13 & .13 & \\
\hline & No setting & .09 & .09 & .00 & .03 & .16 \\
\hline \multirow[t]{3}{*}{ Affect } & Positive & .02 & .00 & .00 & .02 & .02 \\
\hline & Negative & .15 & .07 & .12 & .11 & .11 \\
\hline & None & .80 & .94 & .86 & .90 & .87 \\
\hline First time & Described as firsts ${ }^{c}$ & .10 & .00 & .05 & .05 & .16 \\
\hline \multirow[t]{8}{*}{ Persons } & Mother & .34 & .30 & .30 & .30 & .16 \\
\hline & Fathere & .07 & .20 & .16 & .12 & .11 \\
\hline & Sibling & .15 & .26 & .16 & .25 & .10 \\
\hline & Grandmother & .02 & .07 & .02 & .10 & .03 \\
\hline & Other adults & .15 & .19 & .14 & .19 & \\
\hline & Peer & .13 & .09 & .07 & .14 & \\
\hline & Group & .09 & .13 & .07 & .14 & \\
\hline & No others & .24 & .23 & .30 & .19 & .50 \\
\hline
\end{tabular}

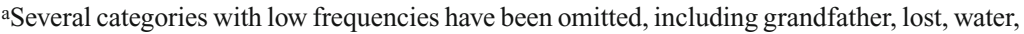
animals, surprise, independence, and birthday parties. $\quad{ }^{\mathrm{b}} \chi^{2}=4.617, p=.032 . \quad{ }^{\mathrm{c}} \chi^{2}=6.18$, $p=.013$. $\mathrm{d} \chi^{2}=3.957, p=.047$. $\quad$ See the text for interaction.

$8.08, p=.003]$. The distribution for women did not differ by culture.

Thematic analysis: I. The impact of culture and gender. The majority of reports referred to personal or family experience stories. The remaining three categories of school, neighborhood, and sociocultural events were collapsed into one category termed wider context. The distribution of these three categories within the culture/ gender subgroups are presented in Figure 2. The focal point of the results was the low proportion of personal experiences reported by black women.

A multinomial logistic regression was performed using dummy codes for culture, gender, and the culture $\times$ gen-

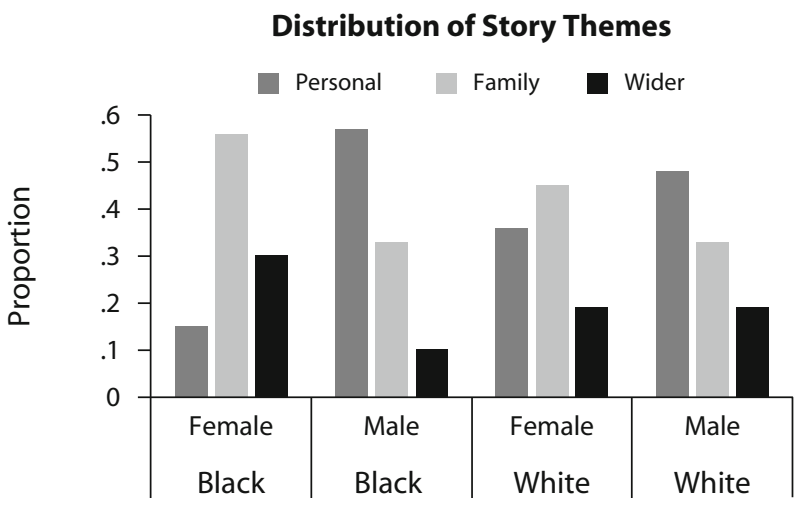

Figure 2. The culture $\times$ gender interaction for story type. The dependent variable is the primary theme coded for earliest memory. der interaction. The dummy codes of 1 female, 0 male, and 1 black, 0 white, resulted in interaction codes of 1 for black females and 0 for the other three groups. The reference category was wider context. The model fit statistic for the interaction was $\chi^{2}(6)=12.29, p=.05$. For the contrast of personal experience with wider context, the parameter estimates for the culture $\times$ gender interaction was $B=-2.36(S E=1.27$; Wald $=3.47, p<.006)$. The exponential term was 10.56 , indicating that the odds of black women reporting a wider experience were considerably higher than those for the other groups

We conducted three logistic regressions comparing each of the thematic categories against the other two combined. For personal experiences, the fit statistic for the interaction term was $\chi^{2}(3)=11.53, p=.009$. The parameter estimate for the interaction term was $B=-1.746(S E=$ 0.93; Wald $=3.55, p<.06$ ). Black women reported personal experiences significantly less often than did black men. No association was found between culture, gender, or the interaction for either family or wider context.

Thematic analysis. II: Comparing story types. An analysis of the characteristics of the different types of experience reports is presented in Table 5. Effects were found for age, word count, references to others, and the ratio of other to self-references. Several specific comparisons are of interest. First, post hoc comparisons using the conservative Bonferroni method indicated that the wider context memories occurred at a significantly older age than did those in the personal and family categories, which did not differ. Second, the total word count was 
Table 5

Story Type Effects on Earliest Memory Characteristics

\begin{tabular}{|c|c|c|c|c|c|c|c|c|}
\hline \multirow[b]{2}{*}{ Variable } & \multicolumn{2}{|c|}{ Personal } & \multicolumn{2}{|c|}{ Family } & \multicolumn{2}{|c|}{ Wider } & \multirow[b]{2}{*}{$F(2,95)$} & \multirow[b]{2}{*}{$p$} \\
\hline & $M_{x}$ & $S D_{x}$ & $M_{x}$ & $S D_{x}$ & $M_{x}$ & $S D_{x}$ & & \\
\hline Age at first memory & 3.77 & 1.45 & 4.00 & 1.58 & 4.89 & 1.64 & 3.41 & .034 \\
\hline Emotions apparent & 0.08 & 0.28 & 0.30 & 0.47 & 0.16 & 0.37 & 2.89 & .061 \\
\hline Total word count & 20.45 & 17.45 & 30.15 & 16.04 & 37.52 & 26.98 & 5.49 & .006 \\
\hline Other references & 0.60 & 0.73 & 2.83 & 1.97 & 3.00 & 2.02 & 18.40 & .000 \\
\hline Self-references & 3.24 & 2.94 & 4.23 & 2.38 & 4.42 & 2.83 & 1.78 & .173 \\
\hline Other/self ratio & 0.24 & 0.34 & 0.82 & 0.56 & 0.69 & 0.44 & 16.41 & .000 \\
\hline
\end{tabular}

significantly lower for the personal experience category than for the family experience category $(d=-0.60)$, which was, in turn, lower than that for the wider context memories $(d=-0.20)$. Third, there was no effect of experience type on self-references. Fourth, references to others showed a clear effect, with more references to others for the family and wider context experiences than for the personal experiences, but the former did not differ. The effect sizes were large $(d=-1.63$ for the comparison of personal and family experiences, and $d=$ -1.38 for the comparison of personal and wider context experiences). Finally, for the other/self ratio variable, the effect sizes were again quite large $(d=-1.23$, for the comparison of personal and family experiences, and $d=$ -1.20 for the comparison of personal and wider context experiences). The family and wider context comparison was not significant.

Autobiographical Memory Questionnaire. There were no significant gender effects for any of the AMQ scales. As is detailed in Table 6, there were cultural differences, however. The black participants rated their experiences higher on three scales: vividly relived, recalled setting, and heard talking. Statistically marginal differences with robust effect sizes were observed for seeing, hearing, and in words.

Two interactions were observed. For emotional intensity $[F(1,95)=6.19, p=.015]$, the comparison between males $\left(M_{\text {intensity }}=1.36\right)$ and females $\left(M_{\text {intensity }}=1.88\right)$ was significant only within the black sample $[t(46)=2.176$, $p=.035, d=0.620]$. Although black and white females

Table 6

Results for Autobiographical Memory Questionnaire Variables

\begin{tabular}{|c|c|c|c|c|c|c|c|}
\hline \multirow[b]{2}{*}{ Scale } & \multicolumn{2}{|c|}{ Blacks } & \multicolumn{2}{|c|}{ Whites } & \multirow[b]{2}{*}{$F$} & \multirow[b]{2}{*}{$p$} & \multirow{2}{*}{$\begin{array}{l}\text { Cohen's } d \\
\text { Ethnicity }\end{array}$} \\
\hline & $M$ & $S D$ & $M$ & $S D$ & & & \\
\hline Reliving & 4.61 & 1.77 & 4.06 & 1.36 & 4.04 & .050 & -0.451 \\
\hline Hear & 4.09 & 1.89 & 3.42 & 1.65 & 2.65 & .059 & -0.443 \\
\hline See & 5.82 & 1.29 & 5.31 & 1.19 & 3.93 & .050 & -0.445 \\
\hline Talking & 3.91 & 1.94 & 3.10 & 1.85 & 4.48 & .037 & -0.503 \\
\hline Emotion & 4.52 & 1.97 & 4.02 & 1.63 & 1.77 & .187 & -0.334 \\
\hline Setting & 6.11 & 1.07 & 5.52 & 1.29 & 5.80 & .020 & -0.542 \\
\hline Remember & 5.73 & 1.40 & 5.27 & 1.33 & 2.72 & .102 & -0.380 \\
\hline In words & 3.91 & 2.04 & 3.46 & 1.31 & 2.57 & .112 & -0.480 \\
\hline Back in time & 4.60 & 1.89 & 4.10 & 1.68 & 3.22 & .075 & -0.362 \\
\hline Coherent & 4.43 & 1.69 & 4.33 & 1.62 & 0.19 & .519 & -0.141 \\
\hline Significant & 3.98 & 2.09 & 3.38 & 1.93 & 2.23 & .139 & -0.444 \\
\hline Really occurred & 5.82 & 1.27 & 5.62 & 1.29 & 0.397 & .530 & -0.262 \\
\hline Rehearsal & 4.09 & 1.82 & 3.94 & 1.61 & 0.203 & .583 & -0.094 \\
\hline Valence & 0.89 & 1.76 & 0.62 & 1.90 & 0.133 & .717 & -0.051 \\
\hline Intensity & 1.61 & 1.01 & 1.85 & 1.23 & 2.37 & .127 & 0.200 \\
\hline
\end{tabular}

did not differ on this variable, white males $\left(M_{\text {intensity }}=\right.$ 2.05) did score higher on intensity than did black males $\left(M_{\text {intensity }}=1.36\right)[t(41)=2.591, p=.013]$. An interaction was also found for coherence $[F(1,95)=3.40, p=$ $.06]$. Black women provided the lowest rating of the four groups. Black men rated their memories as more coherent $\left(M_{\text {coherence }}=5.10\right)$ than did black women $\left(M_{\text {coherence }}=\right.$ 4.00) $[t(42)=2.61, p=.029, d=0.604]$. The comparison between black and white women, however, did not approach significance.

Moderation and mediation. In Study 1, we found no indication that any demographic variable, such as family income or parental education, played a role as a mediator or covariate that would account for the gender $\times$ culture interaction for age at first memory. In the second study, the various content variables represented another class of possible mediators for evaluation. The first step is to demonstrate that a potential mediator could plausibly serve in that role and then to demonstrate a statistical relation between the interaction and the potential mediator. The only plausible candidate mediator was story theme. The significant relationship between story theme and age at first memory is documented in Table 5. Story theme is an unconventional mediator, however, because as a multinomial variable, the information is actually represented as two dichotomous variables.

Two elements of the mediation analysis are unambiguous. Analysis of the path from the interaction term to age at first memory (mediation path c) was significant $\left(r^{2}=\right.$ $.104, p=.005 ; B=1.15, S E=0.35 ; t=3.29, p<.001)$, and as was reported earlier, the interaction of culture and gender was significantly related to story theme (Wald $=$ $6.47, p<.01)$. In this data set, the most appropriate way to examine the path from the mediator to dependent variable is to employ hierarchical linear regression in which the culture $\times$ gender interaction is entered in the first step, followed by two dummy coded variables to represent story theme. The results do not support complete mediation. The first step in the stepwise hierarchical regression reflected the significant effect of the interaction on age at first memory; the second step indicated a nonsignificant increase in variance $\left[r^{2}=.037\right.$ for story theme; $F(1,91)=$ $1.94, p=.15]$. At this step, we found $B=1.04(t=2.88$, $p=.005)$ for the interaction, $B=-0.75(t=1.75, p=$ $.08)$ for personal experience, and $B=-0.750(t=1.82$, $p=.07)$ for wider context. Thus, although story theme is associated with age at first memory, the relationship is not significant when the interaction of culture and gender is first controlled for. 
We conclude that the evidence does not support the hypothesis of complete mediation of the culture $\times$ gender interaction. The evidence suggests that individuals who report events from outside the context of personal experience tend to report older memories and that, in this study, more of those events were reported by black women than by any other group. Thus, it may be that black women have different criteria for retrieval of their first memory than do other groups.

\section{GENERAL DISCUSSION}

As is illustrated in Figure 1, the focal finding of both Study 1 and Study 2 is the significant interaction of culture and gender for age at the time of first memory. In Study 1, the data were collected over the Internet in a completely anonymous fashion; no description of the event was provided. In Study 2, the interaction of culture and gender was replicated in the context of data collected in person; the participants wrote brief accounts of their memories. In Study 1, there was no indication that any demographic variable served as either a mediator or a covariate of this effect. In both studies, the interaction reflected the tendency of black women to be older at the time of their first memory. The effects of both gender in the black sample and culture in the female sample were stronger in Study 2 than in Study 1.

Analysis of the story themes reflected in the memories also indicated a notable culture $\times$ gender interaction. This is illustrated in Figure 2. A low proportion of black women and a very high proportion of black men reported personal experiences. Black women were more likely to report events from a wider context; the participants were older for such events than for personal experiences or family events.

The AMQ results point to a simple main effect: Black participants reported experiencing more detailed and richer memory experiences. The differences might be attributed to a response bias by the black participants. However, black participants also wrote longer accounts, which would fit with the suggestion that they retrieve memories with greater detail. We found significant interactions for two variables: affective intensity and reported coherence. Within the black sample, women reported (1) greater affective intensity and (2) lower coherence; the effects were moderate in both cases. Unlike the results for age at first memory, however, there was no culture effect for females for either variable.

Several other findings are briefly noted here. First, women had higher other/self ratios than did men. This is consistent with the suggestion that autobiographical memories tend to reflect communal contexts more so for women than for men. Second, story theme was associated with several variables, including age at the event, which was younger for personal experiences. Because of this finding, we examined the possibility that story theme could serve as a mediator of the culture $\times$ gender interaction for memory age, but that analysis did not support a mediation account. Finally, the other/self ratio was significantly lower for personal experiences. Given that males of both races primarily reported personal experi- ences, this may partially account for the gender difference in other/self ratios.

In sum, we now have evidence that the comparison of black and white men and women yields a variety of differences in the content and subjective experience of first memories. The findings are not consistent with the hypothesis of a simple main effect of collectivism on either age or content of first memories. Although collectivism may have an indirect influence on autobiographical memory development, it is not immediately apparent why we found variability in that influence between black men and black women. If the main vehicle for delivering the influence of culture is through the reminiscence style of mothers, one hypothesis would be that there are gender differences in the content and/or style of those reminiscences. The available data on gender differences, however, runs counter to this suggestion (Fivush et al., 1996, 2006). Mothers typically elaborate more with daughters, and first memories tend to be younger for women. In the remainder of this discussion, we evaluate several possible explanations for the pattern of findings we observed and the implications for models of early childhood amnesia.

\section{Sampling Bias}

The possibility exists that some form of sampling bias accounts for the interaction. We analyzed the data for the influence of demographic variables other than gender or culture. We found no indication that the culture $\times$ gender interaction could be explained with demographic factors such as family income or parental education.

\section{The Role of the Self}

Our results resemble those of MacDonald et al. (2000), who studied three ethnic groups of New Zealand college students, including Chinese immigrants. In that sample, Chinese women reported older first memories than did Chinese men, much like the black women reporting older first memories in the present study.

MacDonald et al. (2000) proposed an explanation of their results, which they linked to the hypothesis of Howe and Courage (1993) that the emergence of autobiographical memory is linked to the emergence of the self-concept during the 2 nd year of life. They refer to data suggesting that Chinese female students score lower on a measure of self-esteem, but they did not provide a theoretical link between self-esteem in adolescence and the offset of childhood amnesia. Even if such a link were available, their account seems unlikely to explain the present results for black and white Americans. McLeod and Owens (2004) reported that black female adolescents actually score higher than white females on a self-concept measure of competence, and in a large meta-analysis of self-esteem, Twenge and Crocker (2002) reported that both male and female blacks scored higher than whites and that the difference was greater for females. Thus, self-esteem differences do not resemble the memory pattern.

\section{Sociocultural Explanations}

The predominant account of cultural and gender differences observed in prior studies has centered on the remi- 
niscence style of mother-child dialogues about the past, (Bauer, 2007; Fivush, 1991; Fivush \& Buckner, 2003). When gender differences are found, mothers are "more highly elaborative and evaluative of their children's participation in girls than boys" (Nelson \& Fivush, 2004, p. 505). Nelson and Fivush proposed several mechanisms that link higher levels of maternal elaboration and younger first memories. These include a greater number of accessible memories, facilitation of locating the self in time, and more opportunities for mother-child dialogues about the past, which serves to promote the child's appreciation of the unique representation of each individual's past.

The finding of later age at first memory in Asian samples has been hypothesized to reflect the less elaborative, more pedantic style of mother-child reminiscence in Asian cultures, particularly in China, Korea, and India (Mullen \& Yi, 1995; Wang, 2001b). The hypothesized link between childhood experience and age at first memory in adolescence has recently been supported by Jack et al. (2009). The ratio of maternal elaborations to repetitions in mother-child dialogues in the toddler years correlated at -.58 with age at first memory reported at $12-13$ years of age. The number of elaborations alone did not predict age at first memory. Jack et al. also noted that counter to the overall pattern, some mothers whose children reported very early first memories had low elaboration-repetition ratios. This and similar findings suggest that factors such as attachment, temperament, and other individual differences may be important to study, along with reminiscence style (Bauer, 2007).

The dearth of research on mother-child dialogues in a variety of cultural settings limits our conclusions. Only one study has compared black and white mother-child dialogues for reminiscence style (Leyva, Reese, Grolnick, \& Price, 2008). Unfortunately, the participants were all low-income mothers, and the sample was very small. The authors note that the rate of reminiscence behavior was much lower than the rates found in studies of middle-class Caucasian and Asian samples. Perhaps for that reason, they did not report analyses on the standard dependent variables of repetitions and elaborations but relied on a subjective global style rating. Black and white mothers did not differ. Leyva et al. did not report tests for gender differences within the ethnic groups, due to small sample size. Therefore, we cannot draw conclusions about the role of reminiscence style in understanding the present findings and must remain open to alternative explanations.

Some data suggest a similarity of childrearing in AsianAmerican and African-American mothers and a contrast of both groups with Euro-American mothers. When compared with Euro-Americans, African-American mothers have been found to be more intrusive in their parenting style, interrupting the infant's play and trying to steer the infant's behavior in a desired direction (Bradley, Corwyn, McAdoo, \& Garcia Coll, 2001; Ipsa et al., 2004). And in a recent intensive case study of low-income AfricanAmerican mothers, the development of respect in toddlers was a primary childrearing goal (Sharp \& Ipsa, 2009). The parents' description of a respectful child was one who was polite and followed the rules laid down by adults. This is very similar to the description of the parenting goals of Asian mothers reported by Wang (2001a). There is little research on gender differences for these goals. Sharp and Ipsa did report that when black mothers were interviewed when the children were 10 years old, they seem to have lowered their expectation for boys, stating that "boys will be boys" to describe their resignation.

\section{Story Themes and Self-Construal}

Collectivism and individualism are not the sole focus of the messages children receive relevant to self-construal. The alternative domains of self-construal that have been studied include relationships, romanticism, spiritualism, familialism, and social harmony. Kashima et al. (1995) analyzed self-construal in Asian- and European-descended samples. On the basis of factor analyses, they concluded that independent and interdependent dimensions of selfconstruals could be distinguished from a third dimension, relationship self-construal. The relationship dimension is more powerful for distinguishing the self-construal of men and women than are the other two. Cross and Madson (1997) also reported strong gender effects on relationshipbased self-construals. Possible links between relationship self-construal and age at first memory have not been explored, but such efforts may have utility.

We reported earlier that first memories related to schools, neighborhoods, and other, wider contexts were older, on average, than personal or family-oriented experiences. This makes sense from a probability standpoint, in that experience with those contexts increases with age. Although black women sample more from the wider contexts, the mediation analysis found that inclusion of the story type variable does not entirely account for the impact of the culture $\times$ gender interaction for age at first memory.

The observed gender differences in self-construal for the black sample may reflect gender differences in the socialization messages that black boys and girls receive in early childhood (Brown, Tanner-Smith, Lesane-Brown, \& Ezell, 2007; Hughes et al., 2006). Black girls are targeted for collectivist themes concerning racial pride and unity; in contrast, black males are sent messages oriented to the struggles of individuals to overcome discrimination to achieve equality (Thomas \& Speight, 1999). Black mothers are also more firm with daughters than with sons. McAdoo (1988) hypothesizes that girls are being prepared for the eventual role of caretaker of themselves and their future families (McAdoo, 1988). Daughters are also more likely to be securely attached than sons (Barnett, Kidwell, \& Leung, 1998), which may enhance the role of family relationships in identity development. A limiting factor is that the available studies of gender influences have examined only lowincome families, in which the pressures on developing girls and women are different than those found in middle-class families. This limits the generality of the studies.

Contextually, American culture, media, schools, and cultural institutions present powerful messages to all children concerning independence and relationships. The selfconstruals of black and white adolescents of both genders reflect these messages (Coon \& Kemmelmeier, 2001). 
In African-American culture, there is some evidence of gender differences in this message. Young black women receive the strongest collectivist images during childhood socialization experiences.

\section{A Research Agenda}

Two broad sets of factors can be suggested as targets for future research on childhood amnesia, distal and proximal. Distal factors are primarily related to the childhood experiences studied in the sociocultural perspective (Nelson \& Fivush, 2004). In that perspective, the purpose of autobiographical memory is the construction of self-narratives. Information regarding individual autobiographical memories serves as the elements of these self-narratives, and broader social norms and life scripts provide the frameworks that contextualize that information. Distal factors are hypothesized to influence the framework and scripts that are adopted during development. Racial socialization is a distal influence, as is maternal elaboration. Future research on distal influence needs to be more multidimensional and multicultural in order to capture the interplay of possible influences. Longitudinal studies of school-age children would help to clarify these issues greatly.

In addition to distal causes, children, adolescents, and adults may be influenced by more proximal factors located in their current social environment. That is, rather than searching for explanations for cultural differences in age at first memory solely in early childhood experiences, the current contexts of individuals deserve attention. The differences observed between groups may reflect not only what events have "survived" in memory from early childhood (Bauer, 2007), but also the type(s) of events that provide a satisfactory response to the question, "What is your first memory?"

Recent evidence highlights the impact of proximal social influences on memory (Meade \& Roediger, 2002) and on the age at first memory in particular (Malinowski \& Lynn, 1999; T. Peterson, Kaasa, \& Loftus, 2009). These studies show that manipulation of recall context through social pressure or modeling can result in the report of events that fit social criteria but may be false or nonspecific memories. If brief laboratory manipulations produce such results, peer pressure or media content may well shape beliefs about first memories. Retrieval of a particular type of memory may trump search by age. If members of a culture believe that they should report a first memory that corresponds to their current self, there may be a bias to report memories from later childhood. In contrast, if they believe that they should report a first memory that demonstrates their early motor achievements or dependence on adults, they may report memories from a younger age. Experimental manipulations may provide a vehicle for testing hypotheses regarding the influence of specific search criteria.

We have much to learn about first memories beyond their age. The study of more cultures and retrieval contexts will help us to sort out what our observations imply for memory and memory development. We can best conclude that even after a century of research, the study of early memories promises to continue to yield interesting insights into the development and operation of memory.

\section{AUTHOR NOTE}

Please address correspondence regarding this article to J. M. Fitzgerald, Psychology Department, Wayne State University, Detroit, MI 48202 (e-mail: aa1670@wayne.edu).

\section{REFERENCES}

Barnett, D., Kidwell, S. L., \& Leung, K. H. (1998). Parenting and preschool attachment among low-income urban African American families. Child Development, 69, 1659-1671.

Baron, R. M., \& KenNy, D. A. (1986). The moderator-mediator variable distinction in social psychological research: Conceptual, strategic and statistical considerations. Journal of Personality \& Social Psychology, 51, 1173-1182. doi:10.1037/0022-3514.51.6.1173

BAUER, P. J. (2007). Remembering the times of our lives: Memory in infancy and beyond. Mahwah, NJ: Erlbaum.

Bauer, P. J., Burch, M. M., Scholin, S. E., \& Guler, O. E. (2007). Using cue words to inform the distribution of autobiographical memories in childhood. Psychological Science, 18, 910-916. doi:10.1111/j.1467-9280.2007.01999.x

Bradley, R. H., Corwyn, R. F., McAdoo, H. P., \& Garcia Coll, C. (2001). The home environments of children in the United States. Part I: Variations by age, ethnicity, and poverty status. Child Development, 72, 1844-1867. doi:10.1111/1467-8624.t01-1-00382

Brown, T. N., Tanner-Smith, E. E., Lesane-Brown, C. L., \& Ezell, M. E. (2007). Child, parent, and situational correlates of familial ethnic/ culture socialization. Journal of Marriage \& the Family, 69, 14-25.

Bruce, D., Dolan, A., \& Phillips-Grant, K. (2000). On the transition from childhood amnesia to the recall of personal memories. Psychological Science, 11, 360-364. doi:10.1111/1467-9280.00271

Conway, M. A., \& Pleydell-Pearce, C. W. (2000). The construction of autobiographical memories in the self-memory system. Psychological Review, 107, 261-288. doi:10.1037/0033-295X.107.2.261

Coon, H. M., \& Kemmelmeier, M. (2001). Cultural orientation in the United States: (Re) examining differences among ethnic groups. Journal of Cross-Cultural Psychology, 32, 348-364. doi:10.1177/ 0022022101032003006

Cross, S. E., \& MADSON, L. (1997). Models of the self: Self-construals and gender. Psychological Bulletin, 122, 5-37. doi:10.1037/0033 $-2909.122 .1 .5$

FitzGerald, J. M. (1991). A developmental account of early-childhood amnesia. Journal of Genetic Psychology, 152, 159-171.

Fivush, R., \& Buckner, J. P. (2003). Constructing gender and identity through autobiographical narratives. In R. Fivush \& C. A. Haden (Eds.), Autobiographical memory and the construction of narrative self: Developmental and cultural perspectives (pp. 149-168). Mahwah, NJ: Erlbaum.

Fivush, R., \& HADEN, C. A. (Eds.) (2003). Autobiographical memory and the construction of narrative self: Developmental and cultural perspectives. Mahwah, NJ: Erlbaum.

Fivush, R., Haden, C. A., \& Reese, E. (1996). Remembering, recounting and reminiscing: The development of autobiographical memory in social context. In D. C. Rubin (Ed.), Reconstructing our past: An overview of autobiographical memory (pp. 341-359). New York: Cambridge University Press

Fivush, R., Haden, C. A., \& Reese, E. (2006). Elaborating on elaborations: Role of maternal reminiscing style in cognitive and socioemotional development. Child Development, 77, 1568-1588. doi:10.1111/j.1467-8624.2006.00960.x

Freud, S. (1953). The psychopathology of everyday life. In J. Strachey (Ed.), The standard edition of the complete psychological works of Sigmund Freud (Vol. 6). London: Hogarth Press. (Original work published 1901)

Gaines, S. O., Marelich, W. D., Bledsoe, K. L., Steers, W., HenderSon, M. C., Granrose, C. S., ET AL. (1997). Links between culture/ ethnicity and cultural values as mediated by racial/ethnic identity and moderated by gender. Journal of Personality \& Social Psychology, 72, 1460-1476. doi:10.1037/0022-3514.72.6.1460

Henri, V., \& Henri, C. (1898). Earliest recollection. Popular Science, 53, 108-115.

Hofstede, G. (1991). Cultures and organization: Software of the mind. London: McGraw-Hill 
Howe, M. L., \& Courage, M. L. (1993). On resolving the enigma of infantile amnesia. Psychological Bulletin, 113, 305-326. doi:10.1037/ 0033-2909.113.2.305

Hughes, D., Rodriguez, J., Smith, E. P., Johnson, D. J., StevenSON, H. C., \& SPICER, P. (2006). Parents' ethnic-racial socialization practices: A review of research and directions for future study. Developmental Psychology, 42, 747-770. doi:10.1037/0012-1649.42.5.747

ipsa, J. M., Fine, M. A., Halgunseth, L. C., Harper, S., RobinSON, J., BOYCE, L., ET AL. (2004). Maternal intrusiveness, maternal warmth, and mother-toddler relationship outcomes: Variations across low-income ethnic and acculturation groups. Child Development, $\mathbf{7 5}$, 1613-1631. doi:10.1111/j.1467-8624.2004.00806.x

Jack, F., MacDonald, S., Reese, E., \& Hayne, H. (2009). Maternal reminiscing style during early childhood predicts age of adolescents' earliest memories. Child Development, 80, 469-505. doi:10.1111/ j.1467-8624.2009.01274.x

Kashima, Y., Kim, U., Gelfand, M. J., Yamaguchi, S., Choi, C., \& YuKI, M. (1995). Culture, gender, and self: A perspective from individualism-collectivism research. Journal of Personality \& Social Psychology, 69, 925-937. doi:10.1037/0022-3514.69.5.925

Kenny, D. (2009). Moderation. Available at http://davidakenny.net/cm/ moderation.htm.

Kinlstrom, J. F., \& Harackiewicz, J. M. (1982). The earliest recollection: A new survey. Journal of Personality, 50, 134-148. doi:10.1111/j.1467-6494.1982.tb01019.x

Leyva, D., Reese, E., Grolnick, W., \& Price, C. (2008). Elaboration and autonomy support low-income mother's reminiscing: Links to children's autobiographical narrative. Journal of Cognition \& Development, 9, 363-389. doi:10.1080/15248370802678158

MacDonald, S., Uesiliana, K., \& Hayne, H. (2000). Cross-cultural and gender differences in childhood amnesia. Memory, 8, 365-376. doi:10.1080/09658210050156822

MaLinOwSKI, P. T., \& LYNN, S. J. (1999). The plasticity of early memory reports, social pressure, hyponotizability, compliance, and interrogative suggestibility. International Journal of Clinical \& Experimental Hypnosis, 47, 320-345. doi:10.1080/00207149908410040

Markus, H. R., \& Kitayama, S. (1991). Culture and the self: Implications for cognition, emotion, and motivation. Psychological Review, 98, 224-253. doi:10.1037/0033-295X.98.2.224

McAdoo, J. L. (1988). The roles of Black fathers in the socialization of Black children. In H. P. McAdoo (Ed.), Black families (pp. 257-269). Newberry Park, CA: Sage.

McLeod, J. D., \& Owens, T. J. (2004). Psychological well-being in the early life course: Variations by socioeconomic status, gender, and race/ethnicity. Social Psychology Quarterly, 67, 257-278.

Meade, M. L., \& Roediger, H. L., III (2002). Explorations in the social contagion on memory. Memory \& Cognition, 30, 995-1009.

Miller, P. J., Potts, R., Fung, H. D., Hoogstra, L., \& Liang, C. H. (1990). Narrative practices and social construction of self in childhood. American Ethnologist, 17, 292-311. doi:10.1525/ae.1990 $.17 .2 .02 \mathrm{a} 00060$

Mullen, M. K. (1994). Earliest recollections of childhood: A demographic analysis. Cognition, 52, 55-79. doi:10.1016/0010-0277(94) 90004-3

Mullen, M. K., \& Yi, S. (1995). The cultural context of talk about the past: Implications for the development of autobiographical memory. Cognitive Development, 10, 407-419. doi:10.1016/0885-2014 (95)90004-7

NELSON, K. (1986). Event knowledge: Structure and function in development. Hillsdale, NJ: Erlbaum.

Nelson, K., \& Fivush, R. (2000). Socialization of memory. In E. Tulving \& F. I. M. Craik (Eds.), Oxford handbook of memory (pp. 283295). New York: Oxford University Press.

NeLson, K., \& Fivush, R. (2004). The emergence of autobiographical memory: A social cultural developmental theory. Psychological Review, 111, 486-511. doi:10.1037/0033-295X.111.2.486

Oyserman, D., Coon, H. M., \& Kemmelmeier, M. (2002). Rethinking individualism and collectivism: Evaluation of theoretical assumptions and meta-analyses. Psychological Bulletin, 128, 3-72. doi:10.1037/0033-2909.128.1.3

Pennebaker, J. W., Francis, M. E., \& Booth, R. J. (2007). Linguistic Inquiry and Word Count (LIWC): LIWC2007. Austin, TX: LIWC.Net.
Peterson, C., Grant, V. V., \& Boland, L. D. (2005). Childhood amnesia in children and adolescents: Their earliest memories. Memory, 13, 622-637. doi:10.1080/09658210444000278

Peterson, T., Kaasa, S. O., \& Loftus, E. F. (2009). Me too! Social modeling influences on early autobiographical memories. Applied Cognitive Psychology, 23, 267-277.

Reese, E., \& Fivush, R. (1993). Parental styles of talking about the past. Developmental Psychology, 29, 596-606. doi:10.1037/0012 $-1649.29 .3 .596$

Rubin, D. C. (2000). The distribution of early childhood memories. Memory, 8, 265-269. doi:10.1080/096582100406810

Rubin, D. C. (2005). Autobiographical memory methods in cognitive research. In A. E. Wenzel \& D. C. Rubin (Eds.), Cognitive methods and their application to clinical research (pp. 219-241). Washington, DC: American Psychological Association Press. doi:10.1037/10870-014

Rubin, D. C., \& WenZEL, A. E. (1996). One hundred years of forgetting: A quantitative description of retention. Psychological Review, 103, 734-760. doi:10.1037/0033-295X.103.4.734

Sharp, E. A., \& IPSA, J. M. (2009). Inner-city single black mothers' gender-related childrearing expectations and goals. Sex Roles, 60, 656-668. doi:10.1007/s11199-008-9567-3

Thomas, A. J., \& Speight, S. L. (1999). Racial identity and racial socialization attitudes of African American parents. Journal of Black Psychology, 25, 152-170. doi:10.1177/0095798499025002002

Triandis, H. C. (1989). The self and social behavior in differing cultural contexts. Psychological Review, 96, 506-520. doi:10.1037/0033 $-295 X .96 .3 .506$

Triandis, H. C. (1995). Individualism and collectivism. Boulder, CO: Westview.

Twenge, J. M., \& Crocker, J. (2002). Race and self-esteem: Metaanalyses comparing Whites, Blacks, Hispanics, Asians, and American Indians and comment on Gray-Little and Hafdahl (2000). Psychological Bulletin, 128, 371-408. doi:10.1037/0033-2909.128.3.371

VyGotsky, S. (1978). Mind in society: Development of higher psychological processes. Cambridge, MA: Harvard University Press.

WALDFOGEL, S. (1948). The frequency and affective character of childhood memories. Psychological Monographs: General \& Applied, 62(Whole No. 291).

WANG, Q. (2001a). Culture effects of adults' earliest childhood recollection and self-description: Implications of the relation between memory and self. Journal of Personality \& Social Psychology, 81, 220-233. doi:10.1037/0022-3514.81.2.220

WANG, Q. (2001b). "Did you have fun?" American and Chinese motherchild conversations about shared emotional experiences. Cognitive Development, 16, 693-715. doi:10.1016/S0885-2014(01)00055-7

WANG, Q. (2003). Infantile amnesia reconsidered: A cross-cultural analysis. Memory, 11, 65-80. doi:10.1080/741938173

WANG, Q. (2006). Culture and the development of self-knowledge. Current Directions in Psychological Science, 15, 182-187. doi:10.1111/ j.1467-8721.2006.00432.x

Wang, Q., Leichtman, M. D., \& White, S. H. (1998). Childhood memory and self-description in young Chinese adults: The impact of growing up an only child. Cognition, 69, 73-103. doi:10.1016/S0010 $-0277(98) 00061-4$

\section{NOTE}

1. An ANCOVA was conducted on all data for blacks and whites who provided an age for earliest childhood memory. The results replicated those reported: no main effects of ethnicity or culture, but a culture $\times$ gender interaction $\left[F(1,1135)=8.29, M S_{\mathrm{e}}=21.16, p<.05\right]$. Black women $\left(M_{\text {Years }}=4.04, S D=1.85\right)$ reported being older at the time of their first memory than did black men $\left[M_{\text {Years }}=3.61, S D=1.62\right.$; $t(391)=1.969, p<.05, d=0.239]$ and white women $\left[M_{\text {Years }}=3.54\right.$, $S D=1.45 ; t(774)=4.169, p<.05, d=0.310]$. In addition, white men $\left(M_{\text {Years }}=3.78, S D=1.54\right)$ reported being older at first memory than did white women $\left(M_{\text {Years }}=3.54, S D=1.45\right)[t(744)=2.090, p<.01$, $d=0.156]$

(Manuscript received June 29, 2009, revision accepted for publication February 3, 2010.) 